\title{
An Ontological Analysis of the Role of Culture within Green IT
}

\author{
Jagdev Bhogal, William Campbell \\ Faculty of Technology, Engineering and the Environment \\ School of Computing, Telecommunication and Networks \\ Birmingham City University, UK \\ Jagdev.bhogal@bcu.ac.uk \\ William.campbell@bcu.ac.uk
}

\begin{abstract}
This paper explores the relationship between organizational culture, ontologies and the success of green IT initiatives. It investigates the impact of organizational culture on the degree of adoption of Green IT initiatives and on their success. The nature of culture within IT is explored and the effect of culture on the sustainable use of IT is analyzed. The paper presents ontological dimensions from a philosophical perspective by outlining the origins of ontologies. The ontological analysis is also investigated from a computing perspective with respect to semantic web concepts. The relationship between Culture and Green ICT ontologies is explored. It is argued that green IT systems should be designed with an ontology that incorporates cultural issues. The final section of the paper presents concluding remarks and identifies areas of future work.
\end{abstract}

Keywords- Green IT, Sustainability, Information Technology, Organizational culture, IT culture, Ontologies

\section{INTRODUCTION}

The 'green' agenda, is one of the key issues facing the human race. There is widespread acknowledgement that Greenhouse gases have already had a significant effect on the climate, that finite natural resources have been used at an unsustainable rate, and that careless disposal of waste has caused substantial harm.

There have been various laws and concordats addressing sustainability. An important early international treaty was the Kyoto Protocol [1], which required signatories to commit to reducing Greenhouse gases. At the UN 2014 Climate Change Summit, leaders committed to limit global temperature rise to less than 2 degrees Celsius from pre-industrial levels [2].

Individual companies have come under growing pressure to address environmental concerns [3]. An increasing number of companies have adopted a 'Triple Bottom Line' of environment, society and economic performance [4] [5]. Information Technology makes a significant contribution to Greenhouse gas emissions, accounting for around $2 \%$ of global carbon dioxide emissions [6]. But IT can also contribute to reducing pollution through technologies such as 'intelligent buildings'.

Substantial attention has recently been devoted to the impact of organizational culture on the adoption of green initiatives. It has been argued that for companies to systematically to incorporate environmental concerns into their activities requires a major change of corporate culture [7] [8]. Campbell et al. [9] and Campbell et al. [10] explore the impact of organizational culture on the adoption of green IT, using Cameron and Quinn's Competing Values Framework. The current paper extends this work by incorporating ontological perspectives.

The remainder of the paper is structured as follows: Section 2 looks at the green agenda, focusing in particular on green IT. Section 3 explores the nature of organizational culture, and the role of culture within IT. Section 4 examines ontological dimensions. Section 5 discusses the Semantic Web and Section 6 explores the relationship between green ontologies and culture. Finally, there are some concluding observations.

\section{THE GREEN IT AGENDA}

Jenkin et al.[11] draw a distinction between 'Green IT' and 'Green IS'. They define 'Green IT' as the attempt to reduce energy consumption and waste associated with the use of both hardware and software. They define 'Green IS' as the use of information systems to support environmental sustainability initiatives, such as environmental monitoring systems. In this paper, 'Green IT' is used as a generic term covering both the reduction of environmental damage caused by the use of IT, and the use if IT to support environmental objectives.

IT makes a major contribution to the environmental footprints of companies, through both the use of IT and the construction and disposal of IT equipment. A range of national and international laws have been introduced to tackle e-waste. The European Union Waste and Electronic Equipment (WEEE) directive (2003) requires that electronic equipment be refurbished or recycled in an environmentally sound manner. The Japanese Home Electronics Recycling Law (1998) imposes similar requirements to WEEE.

IT data centres are a major source of carbon emissions, producing around 150 million tonnes of carbon annually. In recent years, server virtualization, Software as a Service (SAAS) and Cloud Computing have provided the opportunity for servers to be used more efficiently.

As noted above, IT can make a positive contribution to sustainability. Environmental information systems allow 
variables such as water consumption and pollution to be monitored and supply chain information systems optimize routing and transportation [12].

\section{ORGANIZATIONAL CULTURE}

\section{A. The Impact of Organizational Culture}

The organizational scholar Schein [13] defined organizational culture as: "A pattern of shared basic assumptions that the group learned as it solved its problems of external adaptation and internal integration that has worked well enough to be considered valid and hence to be taught to new members as the correct way to perceive, think and feel in relation to those problems."

Schein identified three levels of culture: Artifacts, those aspects which are on the surface such as dress and can be easily discerned; Espoused Values, i.e. conscious goals, strategies and philosophies; and Basic Assumptions and Values, which exist at a largely unconscious level, are hard to discern and form the inner core of culture. The latter level is the most important and the most difficult to change. Many attempts at organizational change, such as TQM initiatives, fail, because of a failure to change the underlying culture [14].

Cameron and Quinn's 'Competing Values Framework' (CVF) identified two key dimensions of organizational culture: Internal Focus and Integration versus External Focus and Differentiation; and Stability and Control versus Flexibility and Discretion [15] [16]. The CVF has been used in many research studies and has been shown to have a high degree of validity [17]. However, Hartnell et al.'s metaanalytic investigation of the CVF [18], while supporting the view that culture has a major impact on organizational effectiveness, provides only mixed support for the CVF's underlying theory.

The four key culture types identified by the CVF may be summarized as follows (Adapted from [16]):

Hierarchy (Control) - Bureaucratic - The long-term goals of the organization are stability, predictability and efficiency, Formal rules and policies hold the organization together.

Government agencies are typically governed by a hierarchy culture.

Market (Compete) - A results-oriented workplace.

Leaders are aggressive and demanding. The glue that holds the organization together is an emphasis on winning. Success is defined in terms of market share and beating the competition. Clan (Collaborate) - A friendly place to work where people share a lot of themselves. Leaders are thought of as mentors and coaches. The organization is held together by loyalty, tradition, and collaboration. Success is defined in terms of internal climate and concern for people. The organization places a premium on teamwork, participation, and consensus. Adhocracy (Create) - A dynamic, entrepreneurial, riskoriented creative workplace. The glue that holds the organization together is commitment to experimentation and innovation. The emphasis is on being at the leading edge of new knowledge, products, and/or services. Success means producing unique and original products and services.

The Organizational Culture Assessment Tool (OCAI) consists of a questionnaire requiring employees to assess their organization, using an ipsative scale, on six characteristics: Dominant Characteristics, Organizational Leadership, Management of Employees, Organization Glue, Strategic Emphases and Criteria for Success. Based on the results, a CVF profile diagram can be produced.

Campbell et al. [9] discuss the impact of organizational culture on the adoption of green IT initiatives. They argue that companies with adhocracy or clan cultures are more likely to be open to green initiatives, because these cultures are entrepreneurial, non-hierarchical and embrace change. They also argue that green initiatives are more likely to be successful if they are congruent with company culture. They discuss ways in which managers seeking to be greener can effectively take note of cultural issues.

\section{B. IT Culture}

Leidner and Kayworth [19] provide a detailed survey of IT culture. They propose that there are 3 major types of IT culture conflict: System Conflict, between the values embedded in a specific IT system and the values held by a group using the system; Contribution Conflict, between the IT values held by members of a group and the group's general values; and Vision Conflict, between the values embedded in a specific system and a group's general IT values. They argue that it is important to avoid conflict, by seeking alignment between the values of groups, in particular by involving users in the design of systems.

Walsh et al. [20] investigate individual user culture, identifying three key user cultural archetypes: Pro-active, Passive, and Refusal. They argue that managers can improve user acceptance of systems, by tailoring the 'culture migration' of users to their cultural archetypes.

Iivari and Huisman [21] explore the impact of the culture of development teams on the deployment of 'traditional' waterfall systems development methodologies (SDMs). They found a positive association between hierarchical cultures and successful deployment of SDMs and a negative associative between rational (market) cultures and successful deployment. Lopez-Nicolas and Merono-Cerdan [22] looked at the impact of organizational culture on the use of ICT for knowledge management (e.g. computer supported cooperative work). They found that a clan culture was most supportive, but that an adhocracy culture also provided an element of support Gupta [23] found that Indian IT companies were most likely to have a clan culture, followed by an adhocracy culture.

Nickels and Janz [24] used OCAI to investigate the impact of organizational culture on the alignment of business strategy and IT strategy. They found that an overall strong corporate culture, i.e. a culture where there was a high degree of congruence between different areas and levels of the company, supported alignment of IT and business strategy.

It is clear from the above discussion that IT culture has many facets and there is no consensus on its nature or the importance of aligning it with other areas of business. 
Cameron and Quinn [16] found that High Tech IT companies such as Microsoft tended to evolve from an emphasis on adhocracy and clan cultures in their early days to an emphasis on hierarchy and market cultures in their maturity, as they became large corporations with stock market listings.

\section{ONTOLOGICAL DIMENSIONS}

\section{A. The Philosophical Concept of Ontology}

Ontology is the study of what things exist [25]. It has been one of the central concerns of philosophy, going back at least as far as Plato (eg. in "The Republic"]. The most extreme sceptical position is 'phenomenalism', which argues that we cannot really be certain that anything exists, since our knowledge is only of sense-data, rather than the thing itself. A somewhat less sceptical position is that of 'nominalism', which accepts the existence of concrete object such as stones, but not of abstract concepts such as the number 7 .

A widely accepted principle has been that of 'ontological parsimony', namely that one should minimise the number and types of entities introduced. This is linked to the famous dictum of the mediaeval philosopher William Occam, known as 'Occam's razor': "Entities should not be multiplied beyond necessity". Application of this principle might lead to a contention, for example, that it is unhelpful to introduce the concept of 'god', or, in a more practical context, 'stress'.

The twentieth century philosopher, Willard Quine, introduced the highly influential concept of 'ontological commitment', namely acceptance that something existed [26]. He determined the ontological commitments of a statement by re-writing it in first order logic; these become the variables quantified over in the logical statement. This led to the famous motto, 'To be is to be the value of a bound variable'.

A key question has been the role of language. There are essentially two extreme positions. The first is that language is just a tool and has no effect on the real world out there, which can be summarised in Katz's axiom of effability: 'Any thought a person can have can be expressed by some sentence in any language'[27]. The second has become known as 'The Whorf Hypothesis': "We dissect nature along lines laid down in our native language. Language is not simply a reporting device for experience, but a defining framework for it' [28]. The effect of the differing 'colour ontologies' of languages (e.g. the number of shades of blue) on people's perception of colour provides some support for Whorf's view.

\section{B. Applying Ontologies}

An ontology has been shown in [29] to be [currently] the optimal approach to the modelling of context. Ontologies provide consistent vocabularies and world representations necessary for clear communication within knowledge domains [30]. An ontology is more accurately described as "a classification, thesaurus or a set of concept clusters" [31][32]. Gruber [33] defines an ontology to be a 'specification of a conceptualisation'. Gruber explains that ontologies were first used in philosophy then Artificial Intelligence.

Ontologies range from general to domain-specific. WordNet, EuroWordNet and Cyc are examples of a general ontology. Many domain-specific ontologies exist for example in the medical and legal domains. In general, ontologies may be either core ontologies (usable across a range of domains) or domain specific ontologies (e.g., for context modelling in an mobile learning application). Based on subsumption and entailment a core ontology (e.g., a \#Person ontology) can inherit a domain specific ontology (e.g., a \#Mobile_Learning ontology) to create a comprehensive ontology that defines and describes a mobile learning domain..

Advantages offered by ontologies are that they are readily available [34]; they routinely include proper nouns: personal names and place names; many software tools, e.g., Protégé [38] exist to assist in automating the creation and support the evolution of ontologies; finally most ontologies have been defined in a portable language such as XML (eXtensible Markup Language) with the ontology formalised using $\mathrm{RDF} / \mathrm{XML}$ or OWL.

Ontologies are not without their problems. The first issue is related to vocabulary mismatch between the query terms and the concepts in the ontology. A mapping process needs to take place to overcome this problem. Secondly, if an ontology for a particular domain does not exist then a lot of effort is required to construct ontologies from scratch, not just from a technical point of view, but more importantly the process of knowledge extraction from domain experts and arriving at a consensus view. The design and construction of domain ontologies is labour intensive, time consuming and difficult [35]. With the ontological approach, additional expense is incurred due to the new software requirements and the programming training required.

Coherence, stability, and resistance to inconsistency and ambiguity are desirable ontological model characteristics". This is supported by Jones [36] who states that the quality of a knowledge model or thesaurus is of paramount importance. The model must be accurate, stable, comprehensive and up-todate. If a data model does not cover the subject area in a comprehensive way then queries which are relevant to a subject area will not get any results because the model is suffering from some omissions.

\section{Ontologies from a Computing Perspective}

One of the most commonly used ontologies is the Ontology Web Language (OWL) [37]. OWL is a family of languages for knowledge representation. A semantic context modelling ontology created using OWL DL (Description Logic) incorporates the ability to run DL queries. Protégé incorporates functionality using OntoGraph 1.01 [38] to represent an ontology graphically with the object and inverse object properties displayed. This provides a human friendly representation of the ontology showing classes and subclasses and the relationships that exist between them.

Space precludes a detailed discussion on the topic however in Protégé DL Queries are based on SPARQL. DL Queries when run across an ontology provide a basis upon which inference and reasoning can be realised. Thus, Ontology-based Context-Modelling (OBCM) may be used as a nonhierarchical data structure and, where required, may provide for inference and reasoning where the domains specific nature of the domain of interest calls for such an approach to achieve the design requirements. 


\section{v. SEMANTIC WEB}

Ontologies have shown to be beneficial in areas such as Artificial Intelligence (AI) and Natural Language Processing (NLP). According to the W3C, "The Semantic Web provides a common framework that allows data to be shared and reused across application, enterprise, and community boundaries". The term refers to a web of data that can be processed by machines [2]. The Semantic Web involves publishing in languages specifically designed for data: Hypertext Mark-up Language (HTML) describes documents and the links between them. Resource Description Framework (RDF), Ontology Web Lanuage (OWL), and Extensible Mark-up Language (XML), by contrast, can describe objects/concepts such as people, events, automobile parts.

Such technologies can be used to describe the meaning of web page content usually in the form of XML markup tags. The machine-readable descriptions enable content managers to add meaning to the content, i.e., to describe the structure of the knowledge we have about that content. In this way, a machine can automatically process knowledge (instead of text) using deductive reasoning and inferencing processes.

RDF is a general method for defining a graph database. $\mathrm{RDF}$ data is best visualized using RDF graphs. The RDF graph in Figure 1 describes a resource with statements "there is an organization with name Frank Lewis Ltd, size 150 employees and the email address is help@flewis.com." Organizational culture in its simplest form can refer to dresscode which could be formal/casual and language which could have values English/Non-English/All.

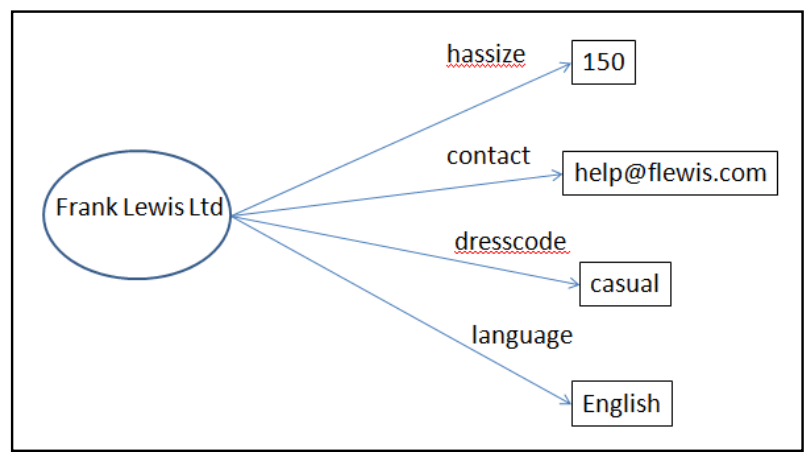

Fig. 1. Simplified RDF Graph Example of Cultural attributes

$\mathrm{RDF}$ graph data can be represented in $\mathrm{RDF} / \mathrm{XML}$ format (see figure 3 ).

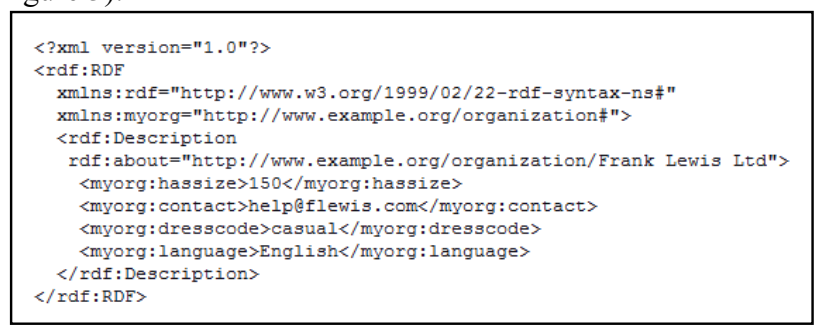

Fig. 2. RDF statements for Figure 1
RDF graph data can also be recorded in serialized form using N-Triples statements [39]. Each statement comprises 3 elements $<$ subject $><$ predicate $><$ object $>$. Figure 3 depicts a set of N-triples statements to represent the RDF graph shown in Figure 1

$$
\begin{aligned}
& <\text { Frank Lewis Ltd }><\text { hassize }><150> \\
& <\text { Frank Lewis Ltd }><\text { contact }><\text { help } @ \text { flewis.com }> \\
& <\text { Frank Lewis Ltd }><\text { dresscode }><\text { casual }> \\
& <\text { Frank Lewis Ltd }<\text { language }><\text { English }>
\end{aligned}
$$

Fig. 3. N-Triples statements

A URI is used to represent each subject and predicate. For example the predicate "hassize" is represented by the URI "http://www.example.org/organization\#hassize". However for reasons of brevity, the URI information has been omitted from the statements in Figure 4.

RDFS uses classes and subclasses to declare hierarchies of data. RDFS describes the "semantics" or meaning of the data. The definition of rdfs:Class is recursive. Literal values such as strings and integers are declared using rdfs:Literal. Hierarchies of classes support inheritance from a class to its subclasses. rdfs:label is an instance of rdf:Property that may be used to provide a human-readable version of a resource's name. rdfs:comment is an instance of rdf:Property that may be used to provide a human-readable description of a resource.

SPARQL Protocol and RDF Query Language (SPARQL) allows for the triples database to be queried. Various tools exist which allow SPARQL queries to be semi-automatically constructed ( for example ViziQuer). In addition, some tools translate SPARQL queries to other query languages, for example to SQL and to XQuery. SPARQL City's SPARQLverse also allows queries directly against nonSPARQL databases such as MongoDB and Cassandra, representing their data as though it is RDF.

The advantages of SPARQL are that it allows users to write queries against data that is in RDF format and it supports inferencing. The entire database is thus a set of "subjectpredicate-object" triples. This is analogous to some NoSQL database's usage of the term "document-key-value", such as MongoDB. To record triplestore in a relational database, all of the triples for a given subject could be represented as a row, with the subject being the primary key and each possible predicate being a column and the object is the value in the cell. However, SPARQL/RDF becomes easier and more powerful for columns that could contain multiple values (like "children"). SPARQL thus provides a full set of analytic query operations for data whose schema is intrinsically part of the data rather than requiring a separate schema definition. 


\section{GREEN ONTOLOGIES AND CULTURE}

An ontological commitment (see discussion above) refers to a relation between a language and certain objects postulated to be extant by that language. The 'existence' referred to need not be 'real', but exist only in a universe of discourse. As an example, legal systems use vocabulary referring to 'legal persons' that are collective entities that have rights. One says the legal doctrine has an ontological commitment to nonsingular individuals. In information systems and artificial intelligence, where an ontology refers to a specific vocabulary and a set of explicit assumptions about the meaning and usage of these words, then an ontological commitment is an agreement to use the shared vocabulary in a coherent and consistent manner within a specific context. In Green IT, the concept 'green' is commonly understood to relate to sustainability. Therefore it would seem sensible to have ontological commitment to concepts like 'green' and 'sustainability'. If we accept 'The Whorf Hypothesis' this commitment will have an effect on the way we perceive the world and act. Do they violate the principle of 'ontological parsimony'? Perhaps the test of whether this commitment is worthwhile is whether the underlying concepts are congruent with our understanding of the world and provide a tool to help us make sense of it and act in it effectively.

Ontologies have been used in Green ICT. Soiryaya [40] created a semi-automatic ontology based on Corporate Social Responsibility Reports. Text Mining was used to analyse the content of 45 reports to identify the important concepts within each document and across the document collection resulting in the construction of a green ICT ontology. The ontology concepts were created using the K-means clustering algorithm. A disadvantage of this algorithm is that it can only measure and group similar categories but it cannot identify the meaning of Green ICT words/sentences. The work only used a limited data set and more work needs to be done in increasing the semantic understanding using Natural Language Processing (NLP) and text mining.

Daouadji et al [41] developed an energy oriented ontology for ICT resources. The resources have 3 categories: computing; storage and network. The end-user requests resources and the semantic analyzer extracts keywords to determine resources and locations. A Bayesian network is used to deal with any confusion/ambiguity by calculating the probability that a resource belongs to each cluster. The ontology based resource discovery for low carbon grid networks outperformed a traditional system which did not take into account Green house gas emissions, location or energy saved.

Jaydianti et al [42] produced a common ontology based on several ontologies available to reduce the search time and hence minimizing the energy used. Toppeta [43] has produced a taxonomy on Green ICT. However the literature on incorporating culture in a green ICT ontology is virtually nonexistent. But the discussion in Campbell et al.[9] suggests that the role of culture in sustainability initiatives is crucial. Green initiatives are more likely to succeed if they are congruent with company culture and certain types of culture are more amenable to green initiatives,

An investigation by Koch and Leidner [44] into the introduction of internal social media systems within a large US company illustrates the importance of culture in a specifically IT context. They found that the introduction of social media resulted in a 'system conflict' between employees' perception of the company culture and their perception of the culture embedded in social media. The company resolved this conflict in two ways: by modifying the social media use to better fit the company culture and by taking steps to modify the company culture. They achieved the former by, for example, making social media use more clearly work-focused and enhancing security features. They achieved the latter through a range of 'Policy based' initiatives, such as incorporating collaboration into employee objectives; 'Socialization based' initiatives such as hosting events to personal relationships between employees; and 'Leadership based' initiatives such as the establishment of social media ambassadors.

Green IT systems are more likely to succeed if they respect the cultural context within which they are used. To accomplish this, they must be designed with an underlying ontology that incorporates cultural issues. The $\mathrm{CVF}$ used in this paper provides a well-established framework for this. Clearly, the CVF types like 'Adhocracy' represent an ontological commitment. The test of whether they are useful in the concept of green IT system, is whether they can be effectively 'operationalized'.

\section{Conclusion AND FUTURE WORK}

Ontologies are useful for knowledge representation and storage of instantiated data. Query languages exist to enable Information to be retrieved from an ontology (competency questions). A major strength of ontologies especially in a large domain is that of automatic inferencing of indirect relationships between numerous ontological concepts. Descriptive logic statements can be used to formalize ontological concepts and relationships.

Future work will entail the development of an ontology that incorporates organizational culture concepts and Green IT concepts. The ontology will be instantiated with a data set that will be gathered via a survey. Competency questions will be set and once the ontology is complete, a query language will be used to satisfy the competency questions. The overall purpose of this work will be to examine the impact of organizational culture on a company's approach to Green IT and evaluate the level of success achieved in implementing Green IT measures.

Another issue is the international dimension. Do the cultural ontologies underlying green IT systems need to take account of different linguistic and cultural contexts? 


\section{References}

[1] UN, "Kyoto protocol," United Nations Convention on Climate Change, 2009

[2] UN Climate Change $\quad$ Summit 2014 http://www.un.org/climatechange/summit/

[3] M. Menguc and L. Ozanne, "Challenges of the green imperative: a natural resource-based approach to the environmental-business performance relationship," Journal of Business Research, vol. 58, pp. 430-438, 2005.

[4] J. Elkington, "Towards the sustainable corporation." California Management Review, vol. Winter, pp. 90-100, 1994.

[5] J. Elkington, "Enter the triple bottom line," in The Triple Bottom Line: Does It All Add up?, A. Henriques and J. Richardson, Eds. Earthscan, London, 2004, pp. 1-16.

[6] M. O’Neill, “Green IT for Sustainable Business Practice”, British Computer Society, 2010.

[7] W. E. Stead and J. G. Stead, Management for a small planet: Strategic decision making and the environment. Newberry Park, CA: Sage, 1992.

[8] J. E. Post and B. W. Altman, "Managing the environmental change process: Barriers and opportunities," Journal of Organizational Change Management, vol. 7, no. 4, pp. 64-81, 1994.

[9] W. M. Campbell, M. Ratcliffe, and P. Moore, "An exploration of theimpact of organizational culture on the adoption of green IT," IEEE International Conference on Green Computing and Communications, Beijing, August 2013

[10] W.M.Campbell, P. Moore, and M. Sharma, Cultural Transformation to Support the Adoption of Green IT, In proc of the IEEE International Conference on Advanced Information Networking and Applications (IEEE AINA 2014), Victoria, Canada.

[11] T. Jenkin, J. Webster, and L. McShane, "An agenda for 'green' information technology and systems research," Information and Organization, vol. 21, pp. 17-140, 2011.

[12] R. T. Watson, M. C. Boudreau, A. Chen, and M. H. Huber, "Green is: Building sustainable business practices," in Information Systems. Athens, GA, USA: Global Text Project, 2008.

[13] E. Schein, Organizational Culture and Leadership. Jossey-Bass, 1992.

[14] K. Cameron, D. Bright, and A. Caza, "Exploring the relationshipbetween organizational virtuousness and performance," American Behavioral Scientist, vol. 47, pp. 766-790, 2004.

[15] R. Quinn and J. Rohrbaugh, "A spatial model of effectiveness criteria: Toward a competing values approach to organizational analysis," Management Science, vol. 29, 1983.

[16] K. Cameron and R. Quinn, Diagnosing and Changing Organizational Culture Based on the Competing Values Framework. Wiley, 2011.

[17] R. Quinn and G. Spreitzer, "The psychometrics of the competing values culture instrument and an analysis of the impact of organizational culture on quality of life," in Research in Organizational Change and Development, R. W. Woodman and W. A. Passmore, Eds. Greenwich Conn.: JAI Press, 1991, vol. 5.

[18] C. A. Hartnell, A. Y. Ou, and A. Kinicki, "Organizational culture and organizational effectiveness: A meta-analytic investigation of the competing values framework's theoretical suppositions," Journal of Applied Psychology, vol. 96, no. 4, pp. 677-694, 2011.

[19] D. Leidner and T. Kayworth, "A review of culture in information systems research: Toward a theory of information technology conflict," MIS Quarterly, pp. 357-399, 2006.

[20] I. Walsh, H. Kefi, and R. Baskervile, "Managing culture creep: Toward a strategic model of user it culture," Journal of Strategic Information Systems, vol. 19, pp. 257-280, 2010

[21] J. Iivari and M. Huisman, "The relationship between organizational culture and the deployment of systems development methodologies," in CAiSE, 2001, pp. 234-250. vol. 53, pp. 509-520, 2011.

[22] C. Lopez-Nicolas and A. Merono-Cerdan, "The impact of organizational culture on the use of ICT for knowledge management," Electron Markets, vol. 19, pp. 211-219, 2009.
[23] B. Gupta, “A comparative study of organizational strategy and culture across industry," Benchmarking: An International Journal, vol. 18, no. 4, pp. 510-528, 2011.

[24] D. Nickels and B. Janz, "Organizational culture: Another piece of the IT-business alignment puzzle," Journal of Information Technology Management, vol. XXI, no. 3, 2010.

[25] N. Effingham, “An Introduction to Ontology”,Polity Press, 2013.

[26] W. Quine, "On What There is", Review of Metaphysics, Routledge, 1948.

[27] D. Bellos,"Is That a Fish in Your Ear", Penguin, 2012.

[28] B. Whorfe, "Thought and Reality", Eastford, 1956

[29] P. Moore, B. Hu, X. Zhu, W. Campbell and M. Ratcliffe, "a survey of context modeling for pervasive cooperative learning", In Proc of the International Symposium on Information Technologies and Applications in Education (ISITAE '07). Kunming, Yuan, China, November 23-25, 2007, K5-1-K5-6, 2007.

[30] G. Leroy, K. Tolle and H. Chen, "Customizable and ontology-enhanced medical information retrieval interfaces", Methods of Information in Medicine, 2000.

[31] M. Bates, "After the Dot-Bomb: getting information retrieval right this time" [online] available at http://www.firstmonday.dk/issues/issue7 7/bates/index.html, 2002]

[32] D. Soergel, "The rise of ontologies or the reinvention of classification", Journal of the American Society for Information Science 50(12), 1119$1120,1999$.

[33] T. Gruber., "A translation approach to portable ontologies", Knowledge Acquisition, 5(2), 199-220, 1993.

[34] J. Bateman, "John Bateman's ontology portal" [online] available at http://www.fb10.uni-bremen.de/anglistik/langpro/webspace/jb/infopages/ontology/ontology-root.htm, 2005.

[35] V. Kashyap, "Design and creation of ontologies for environmental information retrieval", In AOS Workshop, Rome, November, 2001, 1$18,2001$.

[36] S. Jones, "A thesaurus data model for an intelligent retrieval system", Journal of Information Science 19(3), 167-178, 1993.

[37] Protégé. [online] available at http://protege.stanford.edu/, 2013

[38] OntoGraf, [online], Available from: http://protegewiki.stanford.edu/wiki/OntoGraf/ , 2013.

[39] Beckett, D., \& Barstow, A. (2001). N-Triples-W3C RDF Core WG Internal Working Draft. URL:L http://www. w3. org/2001/sw/RDFCore/ntriples.

[40] Soiraya, B. (2012, December). Semi-automatic Green ICT Ontology construction from CSR report. In Computing and Convergence Technology (ICCCT), 2012 7th International Conference on (pp. 711714). IEEE.

[41] Daouadji, A., Nguyen, K. K., Lemay, M., \& Cheriet, M. (2010, October). Ontology-based resource description and discovery framework for low carbon grid networks. In Smart Grid Communications (SmartGridComm), 2010 First IEEE International Conference on (pp. 477-482). IEEE.

[42] Jayadianti, H., Nugroho, L. E., Santosa, P. I., Pinto, C. S., \& Widayat, W. (2013, October). Semantic interrelation in distributed system through green computing ontology. In Information Technology and Electrical Engineering (ICITEE), 2013 International Conference on (pp. 216-220). IEEE.

[43] Donato Toppeta (http://ict4green.wordpress.com/2010/01/15/green-ict1-0-taxonomy/

[44] H.Koch, D.E. Leidner and E.S. Gonzalez, "Digitally enabling social networks: resolving IT-culture conflict." Information Sstems Journal, 2013. 